\title{
Textural performance of crosslinked or reduced-calcium milk protein ingredients in model high-protein nutrition bars
}

\author{
J. C. Banach, ${ }^{*}$ S. Clark, ${ }^{*}$ L. E. Metzger, $†$ and B. P. Lamsal ${ }^{* 1}$ \\ *Department of Food Science and Human Nutrition, lowa State University, Ames 50011 \\ †Department of Dairy Science, South Dakota State University, Brookings 57007
}

\begin{abstract}
Transglutaminase (Tgase) crosslinking and calcium reduction were investigated as ways to improve the texture and storage stability of high-protein nutrition (HPN) bars formulated with milk protein concentrate (MPC) and micellar casein concentrate (MCC). The MPC and MCC crosslinked at none, low, and high levels, and a reduced-calcium MPC (RCMPC) were each formulated into model HPN bars. Hardness, crumbliness, moisture content, $\mathrm{pH}$, color, and water activity of the HPN bars were measured during accelerated storage. The HPN bars prepared with MPC were harder and more cohesive than those prepared with MCC. Higher levels of Tgase crosslinking improved HPN bar cohesiveness and decreased hardening during storage. The RCMPC produced softer, yet crumblier HPN bars. Small textural differences were observed for the HPN bars formulated with the transglutaminase crosslinked proteins or RCMPC when compared with their respective controls. However, modification only slightly improved protein ingredient ability to slow hardening while balancing cohesion and likely requires further improvement for increased applicability in soft-texture HPN bars.
\end{abstract}

Key words: micellar casein concentrate, milk protein concentrate, transglutaminase, protein bar

\section{INTRODUCTION}

High-protein foods are popular among consumers seeking satiety, increased muscle mass, or decreased risk of sarcopenia (Sloan, 2012). Consumers are turning to high-protein nutrition (HPN) bars to conveniently add more protein to their diet. High-protein nutrition bars have used new, trendy protein sources (e.g., in-

Received February 5, 2016.

Accepted April 19, 2016.

${ }^{1}$ Corresponding author: lamsal@iastate.edu sects), but have traditionally relied on dairy and soy ingredients such as concentrates, isolates, and hydrolysates. Protein content typically ranges from 20 to $50 \%$ (wt/wt), whereas carbohydrates (e.g., high-fructose corn syrup), polyols (e.g., glycerol), sugar alcohols (e.g., sorbitol), and lipids (e.g., palm oil) comprise the rest of the formulation (McMahon et al., 2009; Imtiaz et al., 2012).

It is well known that HPN bars, especially those prepared with high-protein milk protein concentrates (MPC; $\geq 80 \%$ protein wt/wt), are texturally unstable during storage (Loveday et al., 2009; Imtiaz et al., 2012). Specifically, HPN bars formulated at $30 \%$ protein (wt/ wt) using MPC that contained $80 \%$ protein rapidly hardened and lost cohesion during storage (Banach et al., 2014, 2016a). Nutritionally, MPC maintain the casein-to-whey protein ratio (80:20) of typical bovine skim milk and are a complete protein with higher digestible indispensable AA score (1.18) than whey protein isolate (1.09), whey protein concentrate (0.97), soy protein isolate $(0.90)$, and pea protein concentrate (0.82; Rutherfurd et al., 2015). The nutritional aspects of MPC and their ability to be ultra-filtered directly from skim milk independent of other processes make HPN bars a primary target application.

Micellar casein concentrates (MCC) are produced by micro-filtering skim milk such that the final spray dried powder has an elevated casein-to-whey protein ratio (92:8; Dairy Management Inc., 2015). Micellar casein concentrates, which are undefined by the global trade atlas and the US Food and Drug Administration, are less studied than MPC (Lagrange et al., 2015). Model HPN bars (45\% protein wt/wt) prepared with MCC remained softer than those formulated whey protein hydrolysate, $\beta$-lactoglobulin, $\alpha$-lactalbumin, whey protein isolate, or sodium caseinate after $10 \mathrm{~d}$ at $37^{\circ} \mathrm{C}$ (Hogan et al., 2012). Agglomerated MCC produced HPN bars (40-50\% MCC powder wt/wt) that were less dough-like and less prone to hardening than those prepared with nonagglomerated MCC over $7 \mathrm{~d}$ storage at $37^{\circ} \mathrm{C}$ (Hogan et al., 2012). Further validation of MCC in HPN bars is needed because, based on protein com- 
position, similar textural performance as MPC would be expected in these applications.

The HPN bar texture changes during storage cannot be attributed to a single mechanistic cause, and although it is a multicomponent system (e.g., protein, carbohydrate, fats, minerals, vitamins), most work has focused on the protein source and ingredient type while the system hardens. Suggested HPN bar hardening mechanisms include moisture migration between constituents, limited free water for complete protein plasticization, entropy-driven macronutrient phase separations, internal disulfide bond formations, and Maillard-induced protein aggregations (Zhou et al., 2008; Loveday et al., 2009; McMahon et al., 2009; Zhou et al., 2013). Mineral (e.g., $\mathrm{Na}^{+}, \mathrm{K}^{+}, \mathrm{Mg}^{2+}$ ) addition or removal, including those natively associated with the protein (e.g., $\mathrm{Ca}^{2+}$ ), may alter the protein's structure, increase internal moisture migration, and subsequently accelerate HPN bar texture change (Book, 2008). Protein hydrolysis has been the main modification technique to impart textural stability during HPN bar storage (McMahon et al., 2009; Rao et al., 2016a). Proprietarily modified (Imtiaz et al., 2012) and extruded MPC (Banach et al., 2014) also improved textural stability when incorporated into model HPN bars. Further, MPC and MCC modification techniques must be explored to not only slow HPN bar hardening during storage, but also to improve cohesion in order to be a preferred protein source for intermediate moisture food applications.

Most protein powders, especially MPC, are modified to improve solubility (Mao et al., 2012; Sikand et al., 2013) as well as dependent functional properties (e.g., emulsification, foaming). However, no clear relationship is apparent between these properties and performance in intermediate-moisture foods such as HPN bars. Transglutaminase (Tgase), an enzyme produced by Streptoverticillium mobaraense, was used to improve the texture of solid foods such as restructured meats, fish pastes, yogurts, breads, and confectionaries (Kieliszek and Misiewicz, 2014; Gaspar and de Góes-Favoni, 2015). Transglutaminase builds texture by crosslinking glutamine residues with intra- or inter-protein lysine residues, which occurs faster and with greater specificity than its acyl transfer and deamidation processes (DeJong and Koppelman, 2002; Gaspar and de GóesFavoni, 2015). Transglutaminase treatment has historically been applied to processed foods seeking textural improvement, but is not commonly used to functionalize protein ingredients for multiple applications (DeJong and Koppelman, 2002). Previously, MPC and MCC were crosslinked by Tgase and functionality was evaluated in processed cheese and yogurt (Salunke, 2013; Salunke et al., 2013a,b), but they were not evaluated in HPN bars.
Transglutaminase crosslinked proteins typically have increased water-holding capacity (Gaspar and de GóesFavoni, 2015). The effect of increased water-holding capacity on HPN bar texture is unknown as water may move toward the protein as driven by water activity $\left(\mathbf{a}_{\mathrm{w}}\right)$ gradient (Gautam et al., 2006; Book, 2008; Li et al., 2008; Hazen, 2010) or toward the low molecular weight, poly-hydroxyl compounds by osmotic pull (Loveday et al., 2009). Reduced-calcium MPC (RCMPC) was manufactured by carbon dioxide acidification of milk protein retentate during ultra-filtration, which solubilized micellar calcium and phosphate (Marella et al., 2015). The RCMPC had improved solubility, which may allow for more rapid hydration during HPN bar production that along with its lower calcium, ash, and net negative charge may limit moisture migration and slow moisture-induced hardening during HPN bar storage.

This study was designed to compare relative textural performance of Tgase crosslinked MPC and MCC, and RCMPC, in a previously used model HPN bar formulation (Banach et al., 2014). Crosslinked protein ingredients will have fewer amine groups available for participation in the Maillard browning reaction (Gerrard, 2002), which may limit formation of protein aggregates that have been associated with HPN bar texture change (Zhou et al., 2013; Banach et al., 2016b). Model HPN bars (30\% protein wt/wt) were prepared with MPC and MCC previously Tgase crosslinked at none, low, and high levels and RCMPC, and hardness, crumbliness, moisture content, $\mathrm{pH}$, color, and $\mathrm{a}_{\mathrm{w}}$ were measured during storage.

\section{MATERIALS AND METHODS}

\section{Materials}

The MPC and MCC powders with none $(\mathbf{N})$, low $(\mathbf{L})$, and high $(\mathbf{H})$ Tgase crosslink levels, including MPC-N ( $74.4 \%$ protein, $3.7 \%$ moisture, $8.9 \%$ lactose), MPC-L (74.4\% protein, $3.9 \%$ moisture, $8.7 \%$ lactose), MPC-H (74.3\% protein, $2.7 \%$ moisture, $8.6 \%$ lactose), MCC-N (77.6\% protein, $3.2 \%$ moisture, $4.4 \%$ lactose), MCC-L (77.6\% protein, $3.6 \%$ moisture, $4.5 \%$ lactose), and MCC$\mathrm{H}$ (76.9\% protein, $3.2 \%$ moisture, $4.5 \%$ lactose), and the RCMPC (71.9\% protein, $3.4 \%$ moisture, $14.4 \%$ lactose) were previously produced (Salunke, 2013; Marella et al., 2015) at South Dakota State University. Urea, SDS, $\beta$-mercaptoethanol, bromophenol blue, and glycerol (99.8\% glycerol, 0.1\% water) were obtained from Fisher Scientific (Waltham, MA). Supplies for SDS-PAGE, including Tris, Precision Plus Protein Standard, Any kD TGX precast gels, Bio-Safe Coomassie Stain, and $10 \times$ Tris/glycine/SDS running buffer, were obtained 
from Bio-Rad Inc. (Hercules, CA). Lactose (200-mesh, 99.8\% lactose, Glanbia Nutritionals, Twin Falls, ID), maltitol syrup (Lycasin 80/55, 51.7\% D-maltitol, 3.0\% D-sorbitol, 24.5\% water, Roquette America, Keokuk, IA), nonhydrogenated palm oil (SansTrans 39, IOI Loders Croklaan, Channahon, IL), and high-fructose corn syrup (CornSweet 55, 55\% fructose, $41 \%$ dextrose, $4 \%$ higher saccharides, $23 \%$ water, Archer Daniels Midland, Decatur, IL) were obtained as a donation for use in this study.

\section{Brief Description of Milk Protein Ingredient Modification}

A full description of protein powder production and modification is available elsewhere (Salunke et al., 2012; Salunke, 2013; Marella et al., 2015). Low (i.e., MPC-L, MCC-L) and high (i.e., MPC-H, MCC-H) crosslinking was accomplished by treating retentates with 0.3 and 3.0 Tgase units per $\mathrm{g}$ of protein, respectively, for $25 \mathrm{~min}$ at $50^{\circ} \mathrm{C}$, which was followed by enzyme inactivation at $72^{\circ} \mathrm{C}$ for $10 \mathrm{~min}$. The controls (i.e., MPC-N, MCC-N) were not treated with Tgase. Separately, RCMPC was produced by injecting skim milk with carbon dioxide gas $(2,200 \mathrm{ppm})$, which was then ultrafiltered and diafiltered ( $\mathrm{pH} 5.7$ ), and like all the protein powders used in this study, was spray dried.

\section{Tgase Crosslink Verification by SDS-PAGE}

Modified proteins were dissolved at $6.7 \mathrm{mg}$ of protein per $\mathrm{mL}$ in Tris buffer $(50 \mathrm{~m} M ; \mathrm{pH} 8.0)$ with denaturants (8 $M$ urea, $2 \%$ SDS, $5 \% \beta$-mercaptoethanol). After being mixed for $4.5 \mathrm{~h}$, protein was diluted to $\sim 4 \mathrm{mg}$ per $\mathrm{mL}$. The solutions were centrifuged at $15,000 \times g$ for $15 \mathrm{~min}$ at $20^{\circ} \mathrm{C}$ and the supernatant was diluted 2 -fold with $2 \times$ reduced sample buffer $(125 \mathrm{~m} M$ Tris, $8 \mathrm{M}$ urea, $20 \%$ glycerol, $2 \%$ SDS, $5 \% \beta$-mercaptoethanol, $0.01 \%$ bromophenol blue). Samples $(4 \mu \mathrm{L})$ and a molecular weight standard $(10 \mu \mathrm{L})$ were loaded onto precast gels and were electrophoresed at $100 \mathrm{~V}$ for $70 \mathrm{~min}$. The proteins were fixed, stained, and de-stained as described elsewhere (Banach et al., 2016b).

\section{Model HPN Bar Preparation}

The HPN bars (30\% protein wt/wt) were prepared $(\mathrm{n}=3)$ with each control, Tgase crosslinked, and RCMPC ingredient serving as the sole protein source in each 250-g batch. Each HPN bar formulation was first standardized to $6 \%$ lactose (wt/wt) by combining the protein powder $(251-271 \mathrm{~g})$ with lactose $(0-28 \mathrm{~g}) .50 .6$ $\mathrm{g}$ of glycerol, $26.9 \mathrm{~g}$ of maltitol syrup, and 1.0 to 2.2 $\mathrm{g}$ of distilled water were stirred into the dry ingredients. Forty-three grams of nonhydrogenated palm oil and $21.8 \mathrm{~g}$ of high-fructose corn syrup were heated together until all the fat melted, and was then mixed into the other constituents. The HPN bar dough was pressed into cylindrical molds (internal diameter $=21$ $\mathrm{mm}$; height $=13 \mathrm{~mm}$ ) and $\mathrm{a}_{\mathrm{w}}$ sample cups, and were transferred to $32^{\circ} \mathrm{C}$ storage the following day. More details about HPN bar production are available elsewhere (Banach et al., 2014).

\section{HPN Bar Texture (Hardness and Crumbliness) Measurement}

Measurements were made on d $0,7,16,28$, and 42 after equilibrating the HPN bars to room temperature $\left(22^{\circ} \mathrm{C}\right)$. Each cylindrical HPN bar sample was compressed 2 times (i.e., texture profile analysis; TPA) to $60 \%$ strain at crosshead speed of $2 \mathrm{~mm} \cdot \mathrm{s}^{-1}$ with a flat plate while force versus time data were recorded (TA-XT2, Texture Technologies, Scarsdale, NY). Hardness was reported as the maximum force $(\mathrm{N})$ during the first compression. After compression, the sample was transferred to a stack of 3-inch $(7.62 \mathrm{~cm})$ sieves and was mechanically shaken for $30 \mathrm{~s}$ (speed 3, Shaker \#18480, CSC Scientific Sieve, Fairfax, VA). The HPN bar crumbliness was reported as the mass percent finer than the top sieve (no. 3.5) with a $5.6 \mathrm{~mm}$ aperture (Banach et al., 2016a). Samples that were too hard for the analyzer to compress to $60 \%$ strain were not analyzed for crumbliness. When the load cell of the texture analyzer reached its maximum, hardness was specified as the force just before stopping. Additional sample measurements $(n \geq 3)$ were attempted as availability allowed.

\section{HPN Bar Color, Water Activity, pH, and Moisture Content Measurement}

Color and $\mathrm{a}_{\mathrm{w}}$ were measured on $\mathrm{d} 0,2,7,16$, and 42 as previously described (Banach et al., 2014). The $a_{w}$ was also measured immediately after manufacture (d -1 ). Dispersions of each HPN bar were prepared in Millipore water (20\% wt/wt) and $\mathrm{pH}$ was measured after mixing for $16 \mathrm{~h}$. Two grams of each HPN bar $(\mathrm{n}=$ 2) was dried at $102^{\circ} \mathrm{C}$ for $24 \mathrm{~h}$ on d $0,7,16$, and 42 , and moisture content was calculated by difference.

\section{Statistical Analyses}

All statistical analyses were conducted using SAS software (version 9.4, SAS Institute Inc., Cary, NC). Log-transformed hardness measurements were analyzed 
using the Lifereg procedure. Protein (i.e., MPC, MCC), crosslink level (i.e., none, low, high), storage day (i.e., $0,7,16,28,42)$, all 2-way interactions, and preparation were the independent variables. In instances when the load cell reached its maximum $(\sim 240 \mathrm{~N})$, the measurement was designated as the right-censoring value. Differences between least squares means were determined, unless otherwise stated, using Tukey's adjusted $P$-value $(P<0.05)$. For HPN bar crumbliness analysis, protein, crosslink, and day were categorized into one variable because some protein $\times$ crosslink $\times$ storage day combinations were inestimable. That is, every HPN bar sample tested on that day from each preparation failed to fracture. Least squares mean estimate statements were written to determine if differences between relevant least squares means were significant $(P<0.05)$. Moisture content, $\mathrm{a}_{\mathrm{w}}, \mathrm{pH}$, and $\mathrm{L}^{*}$ measurements of all the HPN bars were modeled using the mixed procedure. Protein ingredient (i.e., MPC-N, MPC-L, MPCH, MCC-N, MCC-L, MCC-H, RCMPC) and time were the independent variables, and HPN bar preparation was set as the random effect.

\section{RESULTS AND DISCUSSION}

\section{Verification of Tgase-Mediated Crosslink Formation with SDS-PAGE}

As expected, the SDS-PAGE profiles of the controls and RCMPC did not contain any polymerized or aggregated proteins (Figure 1). The MPC and MCC were both crosslinked by Tgase and the portion of crosslinked protein increased with applied enzyme concentration. Highly crosslinked protein polymers, with molecular weight greater than $250 \mathrm{kDa}$, were unable to enter the gel and were only found in MPC-H and MCC-H. Vertical protein band smearing, an indicator of protein polymerization (Hsieh and Pan, 2012), occurred between the $50 \mathrm{kDa}$ marker through just above or just below the $250 \mathrm{kDa}$ maker for the high-level or low-level Tgase crosslinked protein ingredients, respectively. A 10-fold increase in Tgase application increased protein polymer formation between 50 and $250 \mathrm{kDa}$, as visualized by increased stain intensity, and produced high molecular weight polymers incapable of permeating into the gel. However, when MPC-L and MCC-L are compared with their controls, that is MPC-N and MCC-N, respectively, they each contained a higher concentration of crosslinked protein with molecular weight between 50 and $250 \mathrm{kDa}$.

The $\beta-, \kappa^{-}, \alpha_{\mathrm{S}^{-}}$, and $\alpha_{\mathrm{S} 2^{-}}$-casein in MPC and MCC served as the primary substrates for Tgase to crosslink because the globular whey proteins, including $\beta-\mathrm{LG}$,
$\alpha-\mathrm{LA}$, and BSA, are less crosslinkable due to structural constraints (Hsieh and Pan, 2012). Because MCC is richer in casein compared with MPC, it should be more susceptible to Tgase crosslinking, but this was not readily apparent by SDS-PAGE. Corresponding with the newly formed protein polymer concentration, Tgase only slightly polymerized the caseins when applied at a low concentration, and hence the SDS-PAGE protein profiles of MPC-L and MCC-L closely matched their controls. The Tgase treatment polymerized essentially all the $\kappa$-casein in MPC-H and MCC-H, whereas the $\beta$-casein and the $\alpha_{\mathbb{S}}$-caseins were only partially crosslinked. Fresh raw skim milk casein susceptibility to Tgase crosslinking was previously determined as $\beta>\kappa>\alpha_{S_{1}}>\alpha_{S_{2}}$ (Hsieh and Pan, 2012). Another study revealed $\kappa$-casein was polymerized before all the $\beta$-casein in Tgase-treated reconstituted milk (Smiddy et al., 2006). The $\kappa$-casein was polymerized more easily than the other caseins since it preferentially exists on the outside of the micelle and was more accessible to Tgase than the interiorly located caseins (Smiddy et al., 2006). A truncated Tgase polymerization time of $30 \mathrm{~min}$, which is conducive for commercial production, was not long enough to crosslink all the $\beta$-casein in either the MPC or MCC retentate, even though a portion is exteriorly located on the micelle (Smiddy

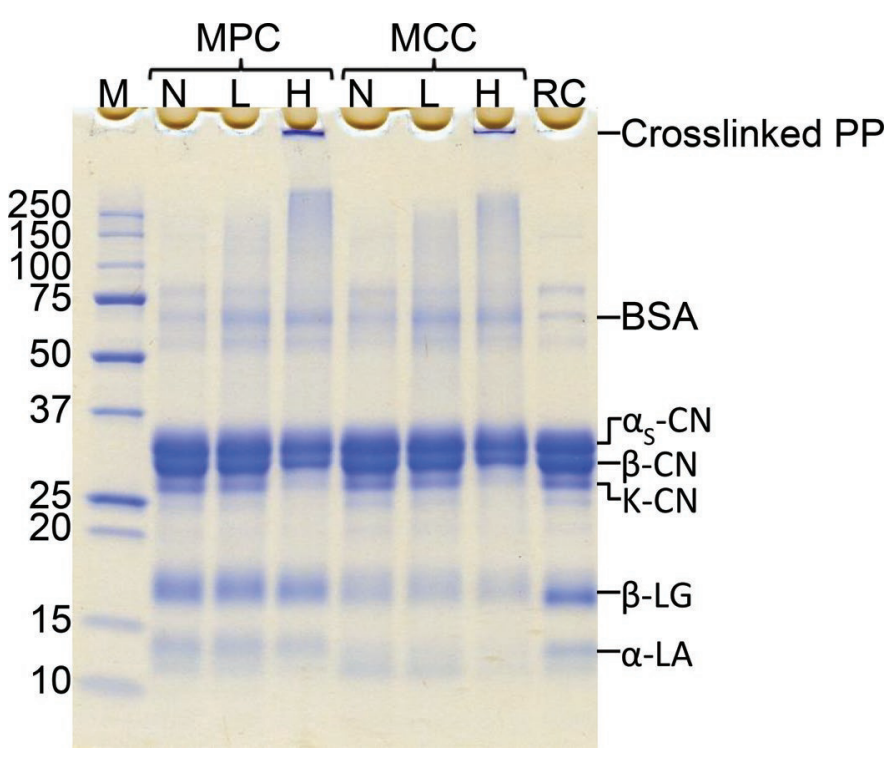

Figure 1. Reduced SDS-PAGE of transglutaminase crosslinked milk protein concentrate (MPC), micellar casein concentrate (MCC), and reduced-calcium MPC (RCMPC). N, L, and $\mathrm{H}=$ none, low, and high transglutaminase crosslink levels, respectively; $\mathrm{M}=$ molecular weight marker $(\mathrm{kDa})$. Crosslinked $\mathrm{PP}=$ transglutaminase crosslinked protein polymers too large to enter the gel. Caseins, from high to low molecular weight, include $\alpha_{S 2}, \alpha_{S 1}, \beta$, and $\kappa$. Color version available online. 
Table 1. High-protein nutrition (HPN) bar (30\% protein wt/wt) moisture content (\%), pH, and $\mathrm{L}^{*}$ color values on $\mathrm{d} 0$ and after $42 \mathrm{~d}$ at $32^{\circ} \mathrm{C}$

\begin{tabular}{|c|c|c|c|c|c|c|}
\hline \multirow[b]{2}{*}{ Protein $^{1}$} & \multicolumn{2}{|c|}{ Moisture } & \multicolumn{2}{|c|}{$\mathrm{pH}$} & \multicolumn{2}{|c|}{$\mathrm{L}^{*}$} \\
\hline & Day 0 & Day 42 & Day 0 & Day 42 & Day 0 & Day 42 \\
\hline MPC-N & $16.1^{\mathrm{a}, \mathrm{z}}$ & $16.7^{\mathrm{a}, \mathrm{z}}$ & $6.6^{\mathrm{a}, \mathrm{z}}$ & $6.5^{\mathrm{a}, \mathrm{z}}$ & $87.5^{\mathrm{a}, \mathrm{z}}$ & $79.5^{\mathrm{ab}, \mathrm{y}}$ \\
\hline MPC-L & $16.4^{\mathrm{a}, \mathrm{z}}$ & $17.0^{\mathrm{a}, \mathrm{z}}$ & $6.5^{\mathrm{a}, \mathrm{z}}$ & $6.5^{\mathrm{a}, \mathrm{z}}$ & $87.7^{\mathrm{a}, \mathrm{z}}$ & $78.5^{\mathrm{bc}, \mathrm{y}}$ \\
\hline MPC-H & $17.5^{\mathrm{a}, \mathrm{z}}$ & $16.3^{\mathrm{a}, \mathrm{z}}$ & $6.5^{\mathrm{a}, \mathrm{z}}$ & $6.4^{\mathrm{a}, \mathrm{z}}$ & $88.5^{\mathrm{a}, \mathrm{z}}$ & $79.0^{\mathrm{abc}, y}$ \\
\hline MCC-N & $17.0^{\mathrm{a}, \mathrm{z}}$ & $16.8^{\mathrm{a}, \mathrm{z}}$ & $6.3^{\mathrm{ab}, \mathrm{z}}$ & $6.5^{\mathrm{a}, \mathrm{z}}$ & $88.3^{\mathrm{a}, \mathrm{z}}$ & $79.9^{\mathrm{ab}, \mathrm{y}}$ \\
\hline MCC-L & $16.5^{\mathrm{a}, \mathrm{z}}$ & $17.0^{\mathrm{a}, \mathrm{z}}$ & $6.6^{\mathrm{a}, \mathrm{z}}$ & $6.6^{\mathrm{a}, \mathrm{z}}$ & $87.7^{\mathrm{a}, \mathrm{z}}$ & $81.3^{\mathrm{a}, \mathrm{y}}$ \\
\hline MCC-H & $16.9^{\mathrm{a}, \mathrm{z}}$ & $17.4^{\mathrm{a}, \mathrm{z}}$ & $6.4^{\mathrm{a}, \mathrm{z}}$ & $6.5^{\mathrm{a}, \mathrm{z}}$ & $88.9^{\mathrm{a}, \mathrm{z}}$ & $81.2^{\mathrm{a}, \mathrm{y}}$ \\
\hline RCMPC & $16.4^{\mathrm{a}, \mathrm{z}}$ & $16.0^{\mathrm{a}, \mathrm{z}}$ & $6.0^{\mathrm{b}, \mathrm{z}}$ & $5.9^{\mathrm{b}, \mathrm{z}}$ & $84.4^{\mathrm{b}, \mathrm{z}}$ & $76.8^{\mathrm{c}, \mathrm{y}}$ \\
\hline \multicolumn{7}{|c|}{$\begin{array}{l}{ }^{a-c} \text { Least squares means not sharing a common superscript within the same column are significantly different } \\
(P<0.05) \text {. }\end{array}$} \\
\hline
\end{tabular}

et al., 2006). $\beta$-Lactoglobulin and $\alpha$-LA were also polymerized by Tgase, as was previously observed (Hsieh and Pan, 2012), but not nearly to the same extent as the caseins as their bands persisted on SDS-PAGE gel. Whey protein polymerization might contribute to the increased concentration of crosslinked protein polymers in MPC-H when compared with MCC-H.

The SDS-PAGE analysis confirmed that MPC and MCC were both crosslinked at high and low levels. It is not possible to predict protein ingredient performance in HPN bars based solely upon their SDS-PAGE profiles. Protein hydrolysates produce softer initial HPN bar texture (Rao et al., 2016b), but with lower molecular weight and no protein aggregates, the system exists in the rubbery state, which is prone to disulfide and Maillard browning induced protein aggregations that have been related to textural hardening during storage (Zhou et al., 2008, 2013). The Tgase modified MPC and MCC possessed altered functionality (Salunke, 2013), which will alter HPN bar texture. Textural stability might be conferred by limiting chemical reactivity by way of increased molecular weight and by preventing the internal production of Maillard-induced protein aggregates.

\section{HPN Bar Moisture Content, $\mathrm{pH}$, and $L^{*}$ Color Values During Storage}

The HPN bar moisture content, averaged across d 0 and 42 , was $16.7 \%$ and was not significantly influenced by protein ingredient or storage time (Table 1), which ruled out moisture loss as a contributor to texture change. The HPN bar $\mathrm{pH}$ did not change during storage $(P>0.05$; Table 1$)$. On d 0 and 42 , the HPN bar made with RCMPC, which was acidified during protein ingredient production, had lower $\mathrm{pH}$ than the other HPN bars $(P<0.05)$. The $\mathrm{L}^{*}$ lightness values decreased $(P$ $<0.05)$ as the samples browned during storage by the Maillard reaction (Table 1). On d 0 and 42, the HPN bar prepared with RCMPC had the lowest $\mathrm{L}^{*}$ value because slightly acidified dairy powders brown faster during storage (Dattatreya and Rankin, 2006). Similar to $\mathrm{L}^{*}$, the $\mathrm{a}^{*}$ and $\mathrm{b}^{*}$ color values (data not shown) of each HPN bar did not differ from their control after equivalent storage. Lower $\mathrm{pH}$ of RCMPC and fewer free amines present in the crosslinked protein ingredients did not slow the visual aspect of Maillard browning. Color compounds do not show through until the late stages of the reaction; regardless, it was unlikely that the development of Maillard-induced protein aggregates (Zhou et al., 2013) was slowed by using these modified protein ingredients. After equivalent storage, each HPN bar likely contained a similar concentration of Maillard-induced protein aggregates and any apparent textural differences would be attributable to another aspect of the modified protein ingredient. The aesthetic aspect of color change is of minor importance because it and any potential off-flavors generated are masked by colorings and flavorings added to commercial products (Rao et al., 2016b).

Average HPN bar $\mathrm{a}_{\mathrm{w}}$ on day manufacture (i.e., $\mathrm{d}-1$ ) was 0.40 , which increased to 0.43 in less than $24 \mathrm{~h}$ (i.e., $\mathrm{d} 0$ ) and to 0.45 after $2 \mathrm{~d}$ (Table 2). These low magnitude increases in $\mathrm{a}_{\mathrm{w}}$ were similar to those observed for other HPN bars, but such a small increase is difficult to relate to overall texture change (McMahon et al., 2009, Banach et al., 2014). The $a_{w}$ of each HPN bar was lower than expected, which may have contributed to the low level of sample browning. 
Table 2. High-protein nutrition (HPN) bar $\left(30 \%\right.$ protein wt/wt) water activity $\left(\mathrm{a}_{\mathrm{w}}\right)$ during storage at $32^{\circ} \mathrm{C}$

\begin{tabular}{lllllll}
\hline & \multicolumn{7}{c}{ Day } \\
\cline { 2 - 7 } Protein $^{1}$ & $-1^{2}$ & 0 & 2 & 7 & 16 & 42 \\
\hline MPC-N & $0.39^{\mathrm{b}, \mathrm{x}}$ & $0.43^{\mathrm{bc}, \mathrm{y}}$ & $0.44^{\mathrm{b}, \mathrm{yz}}$ & $0.44^{\mathrm{bcd}, \mathrm{yz}}$ & $0.46^{\mathrm{ab}, \mathrm{z}}$ & $0.45^{\mathrm{a}, \mathrm{z}}$ \\
MPC-L & $0.39^{\mathrm{ab}, \mathrm{x}}$ & $0.42^{\mathrm{cd}, \mathrm{y}}$ & $0.44^{\mathrm{b}, \mathrm{z}}$ & $0.44^{\mathrm{cd}, \mathrm{z}}$ & $0.45^{\mathrm{b}, \mathrm{z}}$ & $0.45^{\mathrm{a}, \mathrm{z}}$ \\
MPC-H & $0.41^{\mathrm{a}, \mathrm{x}}$ & $0.44^{\mathrm{b}, \mathrm{y}}$ & $0.45^{\mathrm{ab}, y z}$ & $0.45^{\mathrm{abc}, y z}$ & $0.47^{\mathrm{ab}, \mathrm{z}}$ & $0.46^{\mathrm{a}, \mathrm{yz}}$ \\
MCC-N & $0.41^{\mathrm{a}, \mathrm{z}}$ & $0.46^{\mathrm{a}, \mathrm{z}}$ & $0.47^{\mathrm{a}, \mathrm{z}}$ & $0.46^{\mathrm{a}, \mathrm{z}}$ & $0.47^{\mathrm{a}, \mathrm{z}}$ & $0.47^{\mathrm{a}, \mathrm{z}}$ \\
MCC-L & $0.40^{\mathrm{ab}, \mathrm{x}}$ & $0.44^{\mathrm{b}, \mathrm{y}}$ & $0.46^{\mathrm{ab}, \mathrm{z}}$ & $0.45^{\mathrm{ab}, \mathrm{z}}$ & $0.46^{\mathrm{ab}, \mathrm{z}}$ & $0.46^{\mathrm{a}, \mathrm{z}}$ \\
MCC-H & $0.40^{\mathrm{ab}, \mathrm{x}}$ & $0.43^{\mathrm{b}, \mathrm{y}}$ & $0.46^{\mathrm{ab}, \mathrm{z}}$ & $0.46^{\mathrm{ab}, \mathrm{z}}$ & $0.46^{\mathrm{ab}, \mathrm{z}}$ & $0.46^{\mathrm{a}, \mathrm{z}}$ \\
RCMPC & $0.36^{\mathrm{c}, \mathrm{w}}$ & $0.40^{\mathrm{d}, \mathrm{x}}$ & $0.42^{\mathrm{c}, y z}$ & $0.43^{\mathrm{d}, \mathrm{z}}$ & $0.43^{\mathrm{c}, \mathrm{z} z}$ & $0.41^{\mathrm{b}, \mathrm{xy}}$ \\
\hline
\end{tabular}

${ }^{a-d}$ Least squares means not sharing a common superscript within the same column are significantly different $(P<0.05)$

${ }^{\mathrm{w}-\mathrm{z}}$ Least squares means not sharing a common superscript within the same row are significantly different $(P$ $<0.05)$.

${ }^{1}$ The HPN bars were formulated with milk protein concentrate (MPC), micellar casein concentrate (MCC), or reduced-calcium MPC (RCMPC). N, L, and H = none, low, and high transglutaminase crosslink levels, respectively.

${ }^{2}$ Day -1 indicates the day of HPN bar manufacture, whereas d 0 was when samples were moved into $32^{\circ} \mathrm{C}$ storage.

\section{Texture (Hardness and Crumbliness) Changes in HPN Bar During Storage}

The HPN bars hardened during storage (Figure 2), and in addition to time, hardness was significantly influenced by protein, crosslink level, and their 2-way interactions $(P<0.05)$. The HPN bars hardened quicker than expected based on a previous report (Banach et al., 2014). Incompressibility occurred earlier in storage, around d 16, for the HPN bars formulated with MPC-N, for which additional measurements did not initiate sample fracture. The HPN bars from different preparations became too hard for the texture analyzer on different testing days, which was due to the effect of preparation $(P<0.05)$. When additional samples were measured, some tended to fracture whereas others remained incompressible. Inconsistency made it statistically unjustified to include the 3 -way interaction term (i.e., protein $\times$ crosslink $\times$ day) in the Lifereg model and limited hardness contrasts to main effects and 2-way interactions.

Storage of model HPN bars for $42 \mathrm{~d}$ at $32^{\circ} \mathrm{C}$ has been used to approximate $1 \mathrm{yr}$ at $22^{\circ} \mathrm{C}$ ( $\mathrm{Li}$ et al., 2008; McMahon et al., 2009) and at that rate 1 wk at $32^{\circ} \mathrm{C}$ is $\sim 8.7 \mathrm{wk}$ or $\sim 2 \mathrm{mo}$ at $22^{\circ} \mathrm{C}$. Any substantial hardening within 2 mo of manufacture would be unacceptable for a product whose target shelf life is $1 \mathrm{yr}$. On d 0 , MPC formulated HPN bars had mean hardness of $113 \mathrm{~N}$ and were not significantly $(P>0.05)$ softer than the MCC formulated HPN bars that had mean hardness of 121 N. On all other days tested, the HPN bars prepared with MCC were softer than those prepared with MPC $(P<0.05)$. The MCC produced softer HPN bars than several other dairy proteins (Hogan et al., 2012), but those particular MCC formulated samples hardened substantially less over $10 \mathrm{~d}$ at $37^{\circ} \mathrm{C}$ than the present samples did over $6 \mathrm{~d}$ at $32^{\circ} \mathrm{C}$. The $\mathrm{MPC}-\mathrm{H}$ hardened more gradually than MPC-N and MPC-L (Figure 2A) and more similar to the MCC formulated HPN bars (Figure 2B). On average, the HPN bars formulated with MPC-N were harder $(P<0.05)$ than those formulated with MPC-H and MPC-L. Although significant, the small magnitude difference between MPC-N and MPC$\mathrm{L}$ has no practical ability to reduce HPN bar hardness on each storage day (Figure 2A). Even the practicality of MPC-H to reduce HPN bar hardness on each day could be questioned, but it did produce a softer $(P<$ 0.05) HPN bar than MPC-N and MPC-L when averaged over the storage period. No significant difference was found between average HPN bar hardness of MCC$\mathrm{L}$ and MCC-H, but they were both softer $(P<0.05)$ than those formulated with MCC-N. After equivalent storage time, hardness values of the MCC formulated HPN bars closely matched each other (Figure 2B), and such small differences imparted by Tgase crosslinking of MCC did not impart practical softening.

Average HPN bar hardness was inversely related to level of crosslink, increasing from $175 \mathrm{~N}$ for MPC-H/ MCC-H to $193 \mathrm{~N}$ for MPC-L/MCC-L to $218 \mathrm{~N}$ for MPC-N/MCC-N, and all contrasts between levels were significant $(P<0.05)$. The day $\times$ crosslink interactions were compared using Bonferroni's adjustment. The different levels of Tgase crosslinking did not have an effect $(P>0.05)$ on d 0 HPN bar hardness, and if use of Tgase crosslinked proteins did not affect textural stability, this would be seen on each testing day. However, after $7 \mathrm{~d}$ the high Tgase crosslinked proteins produced softer HPN bars than the noncrosslinked proteins $(P$ 
$<0.05)$, but maintained similar hardness as those prepared with the low crosslinked proteins $(P>0.05)$. On d 42 the HPN bars formulated with low and high Tgase crosslinked proteins were both softer $(P<0.05)$ than those prepared using noncrosslinked proteins, but no difference $(P>0.05)$ was found between the Tgase levels. The Tgase crosslinked proteins induced HPN bar brittleness, and because maximum force during compression frequently occurred at the point of fracture, the modification imparted a softening effect. The MPC-H/MCC-H each contained high molecular weight protein polymers (Figure 1) that imparted structural heterogeneity, which created internal weak spots and allowed the system to fracture under lower compressive
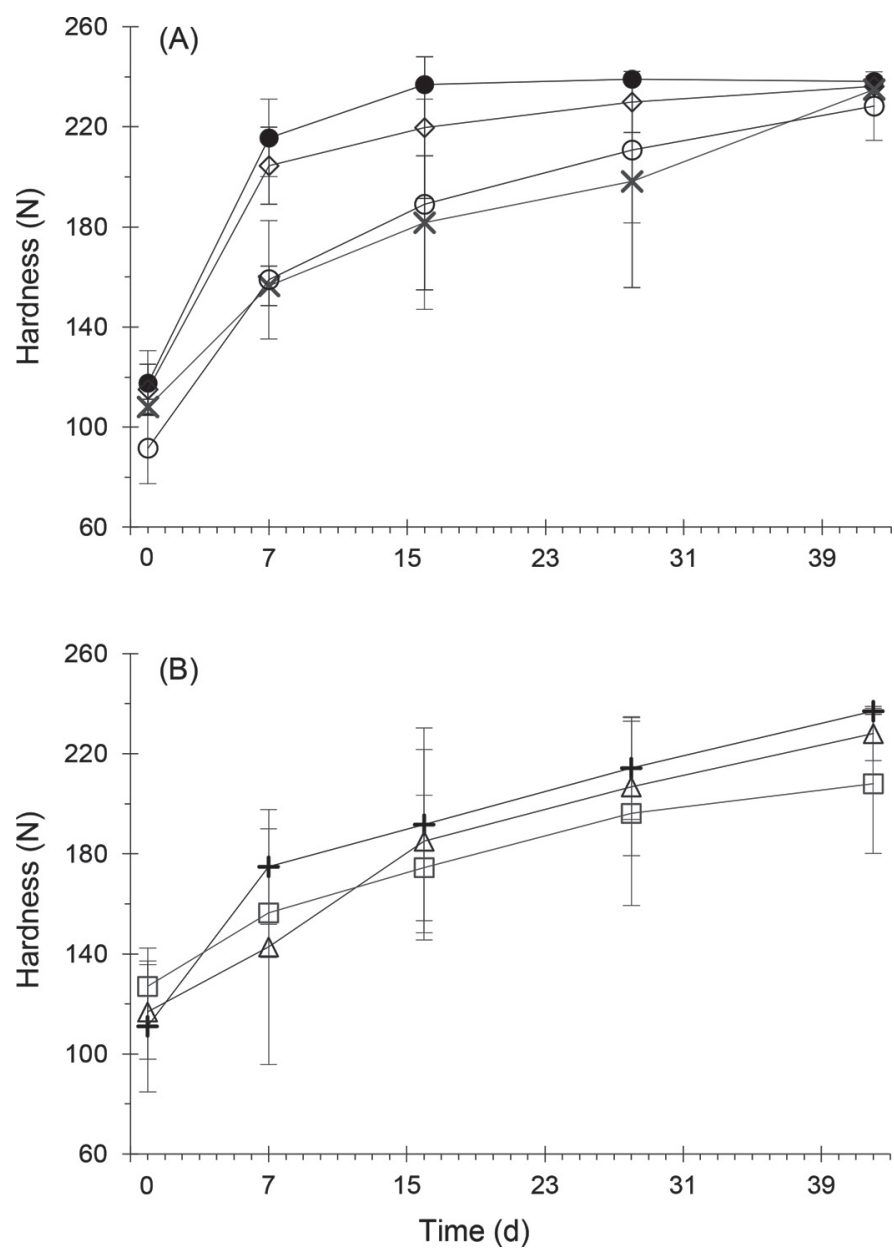

Figure 2. High-protein nutrition (HPN) bar mean hardness during storage at $32^{\circ} \mathrm{C}$. The HPN bars were formulated at $30 \%$ protein (wt/wt) using MPC-N $(\bullet)$, MPC-L $(\diamond)$, MPC-H $(\times)$, RCMPC $(\bigcirc)$, MCC-N $(+)$, MCC-L $(\Delta)$, or MCC-H $(\square)$. MPC = milk protein concentrate $(\mathrm{A}) . \mathrm{MCC}=$ micellar casein concentrate $(\mathrm{B}) . \mathrm{N}, \mathrm{L}$, and $\mathrm{H}$ $=$ none, low, and high transglutaminase crosslink levels, respectively. $\mathrm{RCMPC}=$ reduced-calcium milk protein concentrate. Error bars represent $\pm 1 \mathrm{SD}(\mathrm{n}=3)$. force (Purwanti et al., 2010). Other HPN bars formulated with low molecular weight hydrolysates are soft and pliable, but are susceptible to chemical changes, such as disulfide bond formations (Zhou et al., 2008) and Maillard-induced protein aggregations (Zhou et al., 2013) that occur with hardening. These changes, as well as free amine reduction, were not related to the texture change of MPC formulated HPN bars, but they did occur during storage (Loveday et al., 2009; Banach et al., 2016b). Protein crosslinking increases ingredient molecular weight, but decreases molecular mobility and chemical reactivity within HPN bars. This means that internal disulfide bond formations and Maillardinduced protein aggregations would be slowed when crosslinked proteins are used in HPN bars. Maillardinduced protein aggregations might also be slowed because Tgase crosslinked proteins have lower initial free amine content.

Overall, the model HPN bars prepared with either MPC or MCC were crumbly and lacked cohesion. Crumbliness and cohesiveness are sparsely reported in the HPN bar literature. Sieve analysis results of twice-compressed HPN bars were previously correlated with trained panel measured in-hand crumbliness and in-mouth cohesiveness (Banach et al., 2016a). Crumbliness increased substantially after $1 \mathrm{wk}$ and then increased at a slower rate (Figure 3). The MCC produced HPN bars that were, on average, more crumbly than those made with MPC $(P<0.05)$. Decreased cohesion is a drawback of using MPC in HPN bars (Imtiaz et al., 2012; Banach et al., 2016a), and the MCC under current study only worsened this texture attribute. Proprietarily functionalized whey protein concentrate added to MPC decreased crumbliness and increased cohesiveness of a HPN bar (Imtiaz et al., 2012). Whey proteins are removed during MCC production; because they possess an ability to impart cohesiveness, it was not surprising that MCC produced crumblier HPN bars.

The Tgase crosslinking of protein was expected to improve HPN bar cohesiveness and decrease crumbliness by adding structure. The Tgase crosslinked proteins produced HPN bars that were less crumbly than the control $(P<0.05)$ and a higher level of crosslinking imparted greater cohesion $(P<0.05)$. Data required careful analysis because HPN bars became incompressible at different storage times. Some crumbliness estimates were based on a single preparation, whereas others were inestimable, for example, the HPN bar formulated with MPC-N after d 16. Mechanical force generated during sieving/shaking was insufficient to break an incompressible sample and it was completely retained on the top sieve. Although not crumbly in 

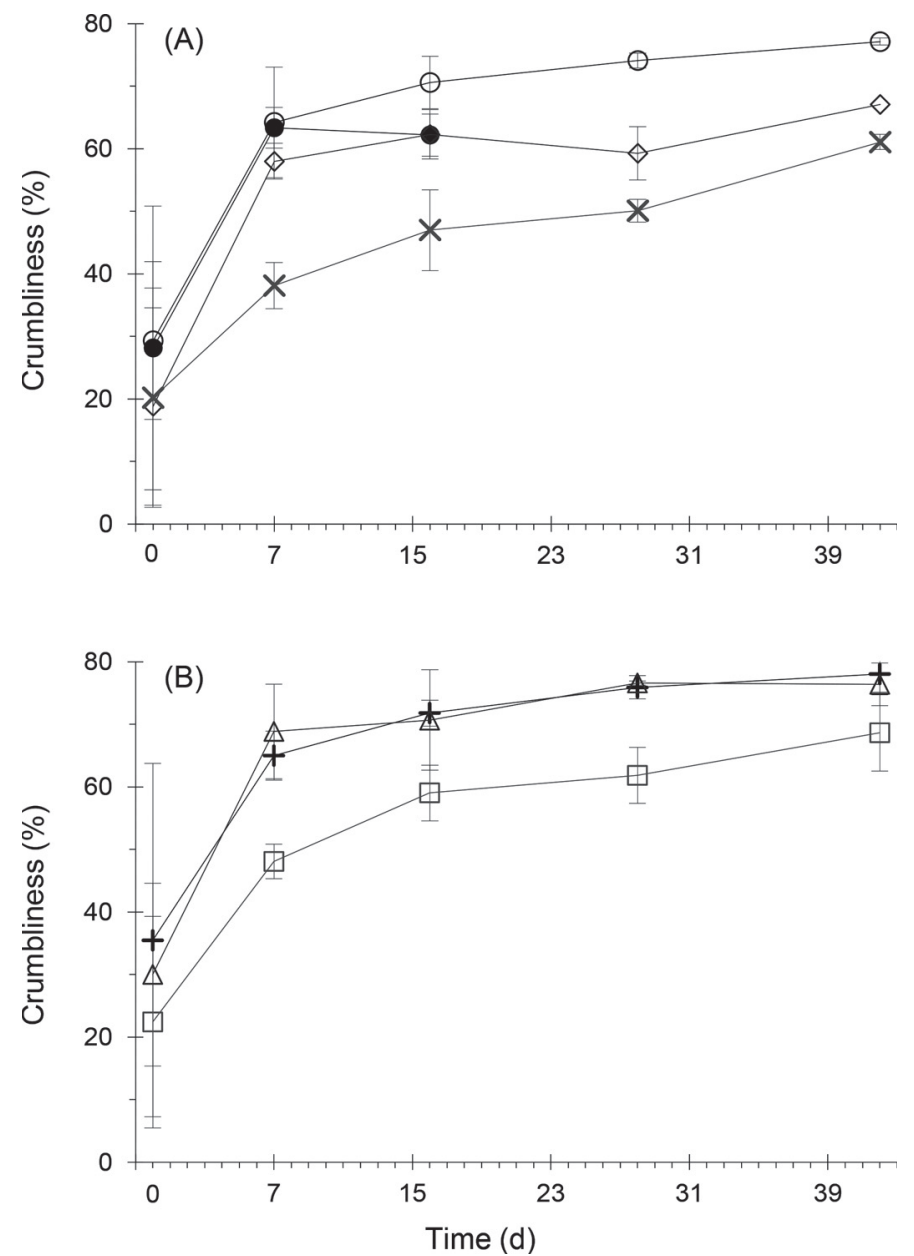

Figure 3. High-protein nutrition (HPN) bar mean crumbliness during storage at $32^{\circ} \mathrm{C}$. The HPN bars were formulated at $30 \%$ protein (wt/wt) using MPC-N $(\bullet)$, MPC-L $(\diamond)$, MPC-H $(\times)$, RCMPC $(\bigcirc)$, MCC-N $(+)$, MCC-L $(\Delta)$, or MCC-H $(\square)$. MPC = milk protein concentrate $(\mathrm{A}) . \mathrm{MCC}=$ micellar casein concentrate $(\mathrm{B}) . \mathrm{N}, \mathrm{L}$, and $\mathrm{H}$ $=$ none, low, and high transglutaminase crosslink levels, respectively. $\mathrm{RCMPC}=$ reduced-calcium milk protein concentrate. Error bars represent $\pm 1 \mathrm{SD}(\mathrm{n}=3)$

terms of the assay, these samples would be deemed unacceptable by hardness alone, and being texturally irrelevant, crumbliness was not reported for samples that did not break during compression. On each testing day, HPN bar crumbliness values of MPC-H were compared with MPC-L and those for MCC-H were compared with MCC-L. Crumbliness of the HPN bars prepared with MCC-N and MCC-L did not differ $(P>$ 0.05 ) on each day tested (Figure 3B). The HPN bars formulated with MPC-H or MCC-H regularly fractured during TPA, and while fines persisted, they were more cohesive than MPC-L or MCC-L, respectively, yet contrast significance varied with testing day. The MPC-H or MCC-H HPN crumbliness was not different $(P>$
0.05) than MPC-L or MCC-L on d 0, respectively, but on $\mathrm{d} 7$ and $\mathrm{d} 16$ those differences were significant $(P<$ $0.05)$. The HPN bar formulated with MCC-H was also less crumbly than MCC-L on d $28(P<0.05)$.

Crumbliness leveled off as d 42 approached, and on that day, no differences $(P>0.05)$ were found between MPC-H or MCC-H and MPC-L or MCC-L, respectively. Using Tgase crosslinked protein ingredients in HPN bars reduced the rate in which crumbliness developed and improved overall cohesiveness. The Tgase was inactivated after MPC and MCC were crosslinked, so internal Tgase crosslinking does not occur in the HPN bar during storage. The Tgase improved the cohesiveness of an emulsified meat system when added in its active form (Herrero et al., 2008). Because the HPN bars had low moisture (Table 1), low $\mathrm{a}_{\mathrm{w}}$ (Table 2), and stable $\mathrm{pH}$ (Table 1), protein gelation cannot occur during storage. Caseinate gels produced by glucono delta-lactone acidification were more cohesive when produced with Tgase-crosslinked caseinate (Song and Zhao, 2013). Other than inhibition or slowing of the texture change mechanisms discussed for hardening, it was not possible to pinpoint why MPC-H and MCC-H produced a more cohesive HPN bar.

\section{Reduced-Calcium MPC: Effect on Bar Texture}

The RCMPC produced HPN bars that were more powdery, drier to the touch, and less adhesive (data not shown) on each testing day than all the other models. It was important to balance bar constituents for shelf stability (i.e., $\mathrm{a}_{\mathrm{w}}<0.65$ ) while maintaining a formulation suitable for all the protein ingredients being evaluated, yet similar to those previously used for MPC formulated HPN bars (Imtiaz et al., 2012; Banach et al., 2014). The MPC-N was not produced from the same lot of skim milk as RCMPC, but it sufficed as its control. The RCMPC slowed HPN bar hardening (Figure 2A), especially when compared with MPC-N, but values still approached the maximum measurable by the current texture analyzer as storage time neared 42 d. Standard deviation between preparations was high and thus it was unlikely that the hardness of the RCMPC formulated HPN bar differed from MPC-N on d 0, 16, 28, and 42. Apparently, its hardness was only lower than MPC-N on d 7 (Figure 2) or $\sim 2$ mo at $22^{\circ} \mathrm{C}$. Whereas RCMPC produced a softer HPN bar for the short term, it was the crumbliest one evaluated (Figure $3 \mathrm{~A}$ ). Although softness was imparted initially, RCMPC did not improve HPN bar cohesiveness, and thus reducing the calcium content of MPC will not improve its ability to serve as a predominant protein in these applications. However, RCMPC might be blended with 
other protein ingredients to potentially impart softening or, if desired, a crumbling effect.

\section{CONCLUSIONS}

In this study, MPC and MCC, previously crosslinked at low and high levels, plus one RCMPC were texturally evaluated in a model HPN bar. The MPC and MCC produced HPN bars that progressively hardened and lost cohesion during storage. Overall, those formulated with MPC were harder and more cohesive than those made with MCC. The Tgase crosslinked proteins decreased HPN bar hardness and decreased the development of crumbliness during storage. More protein crosslinking lowered peak force during compression, after which the sample was characterized as being less crumbly. However, as storage time progressed, the HPN bars formulated with the modified protein ingredients behaved with greater textural similarity as their respective controls. The RCMPC produced a softer and crumblier HPN bar when compared with control MPC. We conclude that the small magnitude changes in HPN bar texture that resulted from using Tgase crosslinked MPC or MCC, or RCMPC, did not improve stability during storage and that these modified protein ingredients have no practical advantage over their unmodified controls in HPN bars.

\section{ACKNOWLEDGMENTS}

The protein ingredients used in this study were produced at South Dakota State University by Prafulla Salunke and Chenchaiah Marella. This project was partially supported by Dairy Research Institute award \#H003889501 through the University of Minnesota and partially by the Iowa State University Agricultural Experiment Station.

\section{REFERENCES}

Banach, J. C., S. Clark, and B. P. Lamsal. 2016a. Instrumental and sensory texture attributes of high-protein nutrition bars formulated with extruded milk protein concentrate. J. Food Sci. 81:S1254S1262. http://dx.doi.org/10.1111/1750-3841.13270.

Banach, J. C., S. Clark, and B. P. Lamsal. 2016b. Microstructural changes in high-protein nutrition bars formulated with extruded or toasted milk protein concentrate. J. Food Sci. 81:C332-C340.

Banach, J. C., S. Clark, and B. P. Lamsal. 2014. Texture and other changes during storage in model high-protein nutrition bars formulated with modified milk protein concentrates. LWT Food Sci. Tech. (Paris) 56:77-86.

Book, S. 2008. Protein Ingredients for Health and Texture. Prepared Foods. Accessed Jan. 20, 2016. http://www.preparedfoods. com/articles/105676-protein-ingredients-for-health-and-texturefebruary-2008.

Dairy Management Inc. 2015. Micellar casein concentrate. U.S. Dairy Export Council. Accessed Jan. 20, 2016. http://www. thinkusadairy.org/resources-and-insights/resources-and-insights/ product-resources/micellar-casein-concentrate-ingredients.

Dattatreya, A., and S. A. Rankin. 2006. Moderately acidic pH potentiates browning of sweet whey powder. Int. Dairy J. 16:822-828.

DeJong, G. A. H., and S. J. Koppelman. 2002. Transglutaminase catalyzed reactions: Impact on food applications. J. Food Sci. 67:2798-2806.

Gaspar, A. L. C., and S. P. de Góes-Favoni. 2015. Action of microbial transglutaminase (MTGase) in the modification of food proteins: A review. Food Chem. 171:315-322.

Gautam, A., A. C. Garcia, and R. J. Hander, inventors. 2006. Nutrition bar. Slim-Fast Foods Company, assignee. US 20060115554 A1.

Gerrard, J. 2002. Protein-protein crosslinking in food: Methods, consequences, applications. Trends Food Sci. Technol. 13:391-399.

Hazen, C. 2010. Texture solutions for snack bars. Food Product Design 6:40-58.

Herrero, A. M., M. I. Cambero, J. A. Ordóñez, L. de la Hoz, and P. Carmona. 2008. Raman spectroscopy study of the structural effect of microbial transglutaminase on meat systems and its relationship with textural characteristics. Food Chem. 109:25-32.

Hogan, S. A., V. Chaurin, B. T. O'Kennedy, and P. M. Kelly. 2012. Influence of dairy proteins on textural changes in high-protein bars. Int. Dairy J. 26:58-65.

Hsieh, J. F., and P. H. Pan. 2012. Proteomic profiling of microbial transglutaminase-induced polymerization of milk proteins. J. Dairy Sci. 95:580-589.

Imtiaz, S. R., B. Kuhn-Sherlock, and M. Campbell. 2012. Effect of dairy protein blends on texture of high protein bars. J. Texture Stud. 43:275-286.

Kieliszek, M., and A. Misiewicz. 2014. Microbial transglutaminase and its application in the food industry. A review. Folia Microbiol. (Praha) 59:241-250.

Lagrange, V., D. Whitsett, and C. Burris. 2015. Global market for dairy proteins. J. Food Sci. 80(Suppl. 1):A16-A22.

Li, Y., K. Szlachetka, P. Chen, X. Lin, and R. Ruan. 2008. Ingredient characterization and hardening of high-protein food bars: An NMR state diagram approach. Cereal Chem. 85:780-786.

Loveday, S. M., J. P. Hindmarsh, L. K. Creamer, and H. Singh. 2009. Physicochemical changes in a model protein bar during storage. Food Res. Int. 42:798-806.

Mao, X. Y., P. S. Tong, S. Gualco, and S. Vink. 2012. Effect of $\mathrm{NaCl}$ addition during diafiltration on the solubility, hydrophobicity, and disulfide bonds of $80 \%$ milk protein concentrate powder. J. Dairy Sci. 95:3481-3488.

Marella, C., P. Salunke, A. C. Biswas, A. Kommineni, and L. E. Metzger. 2015. Manufacture of modified milk protein concentrate utilizing injection of carbon dioxide. J. Dairy Sci. 98:3577-3589.

McMahon, D. J., S. L. Adams, and W. R. McManus. 2009. Hardening of high-protein nutrition bars and sugar/polyol-protein phase separation. J. Food Sci. 74:E312-E321.

Purwanti, N., A. J. van der Goot, R. Boom, and J. Vereijken. 2010. New directions towards structure formation and stability of protein-rich foods from globular proteins. Trends Food Sci. Technol. 21:85-94.

Rao, Q., A. K. Kamdar, M. Guo, and T. P. Labuza. 2016a. Effect of bovine casein and its hydrolysates on hardening in protein dough model systems during storage. Food Contr. 60:621-628.

Rao, Q., A. K. Kamdar, and T. P. Labuza. 2016b. Storage stability of food protein hydrolysates $-\mathrm{A}$ review. Crit. Rev. Food Sci. Nutr. 56:1169-1192. http://dx.doi.org/10.1080/10408398.2012.758085.

Rutherfurd, S. M., A. C. Fanning, B. J. Miller, and P. J. Moughan. 2015. Protein digestibility-corrected amino acid scores and digestible indispensable amino acid scores differentially describe protein quality in growing male rats. J. Nutr. 145:372-379.

Salunke, P. 2013. Impact of transglutaminase on the functionality of milk protein concentrate and micellar casein concentrate. $\mathrm{PhD}$ Thesis. Dairy Science Department, South Dakota State Univ., Brookings.

Salunke, P., C. Marella, and L. E. Metzger. 2012. Effect of transglutaminase treatment on the functionality of MPC and MCC: Process cheese product slice formulations. J. Dairy Sci. 95(Suppl. 2):23. 
Salunke, P., C. Marella, and L. E. Metzger. 2013a. Effect of transglutaminase treatment on the functionality of MPC and MCC: Yogurt formulation. J. Dairy Sci. 96(E-Suppl. 1):233. (Abstr.)

Salunke, P., C. Marella, and L. E. Metzger. 2013b. Effect of transglutaminase treatment on the functionality of MPC and MCC: Imitation mozzarella cheese manufactured in twin screw cooker. J. Dairy Sci. 96(E-Suppl. 1):233-234. (Abstr.)

Sikand, V., P. S. Tong, and J. Walker. 2013. Effect of adding salt during the diafiltration step of milk protein concentrate powder manufacture on mineral and soluble protein composition. Dairy Sci. Technol. 93:401-413.

Sloan, A. E. 2012. Top 10 functional food trends. Food Tech. 4:24-41.

Smiddy, M. A., J.-E. G. H. Martin, A. L. Kelly, C. G. de Kruif, and T.

Huppertz. 2006. Stability of casein micelles cross-linked by transglutaminase. J. Dairy Sci. 89:1906-1914.
Song, C.-L., and X.-H. Zhao. 2013. Rheological, gelling and emulsifying properties of a glycosylated and cross-linked caseinate generated by transglutaminase. Int. J. Food Sci. Technol. 48:2595-2602.

Zhou, P., M. Guo, D. Liu, X. Liu, and T. P. Labuza. 2013. Maillardreaction-induced modification and aggregation of proteins and hardening of texture in protein bar model systems. J. Food Sci. 78:C437-C444.

Zhou, P., X. Liu, and T. P. Labuza. 2008. Effects of moisture-induced whey protein aggregation on protein conformation, the state of water molecules, and the microstructure and texture of high-proteincontaining matrix. J. Agric. Food Chem. 56:4534-4540. 